\title{
Treino físico promove aumento de peso em ratos desnutridos sem causar stress oxidativo
}

\author{
Physical training promotes weight gain in malnourished rats without in- \\ ducing oxidative stress
}

\author{
Emerson Cruz de Oliveira1, ${ }^{1 *}$, Allan Cristian Gonçalves ${ }^{1,3}$, Maísa Silva ${ }^{1,4}$, Maria Lúcia Pe- \\ drosa $^{1,5}$, Marcelo Eustáquio Silva ${ }^{1,6}$
}

ARTIGO ORIGINAL | ORIGINAL ARTICLE

\begin{abstract}
O objetivo do presente trabalho foi estudar o efeito do exercício no stress oxidativo de ratos desnutridos. Trinta e duas ratas Fischer foram igualmente divididas em Controlo Sedentário (CS), Controlo Treinado (CT), Desnutrido Sedentário (DS) e Desnutrido Treinado (DT). O protocolo de treino consistiu na prática de natação ao longo de trinta minutos contínuos diários, cinco dias por semana durante oito semanas. Os animais do grupo DT apresentaram maior aumento de peso e peso final mais elevado do que os animais do grupo DS. Os valores de superóxido dismutase e sulfidrilas totais não mostraram aumento de stress por efeito do treino, da mesma forma que não foram evidenciados danos hepáticos. Os animais CS e DS apresentaram valores de glicose sérica mais elevados do que os animais CT e DT, respetivamente. Já o teste oral de tolerância à glicose confirmou o aumento significativo apenas para o grupo CS em relação ao CT. Conclui-se que o treino físico provocou o aumento de peso e influenciou o peso final dos animais desnutridos sem aumentar o stress oxidativo no soro e sem modificar a ingestão alimentar ou causar danos hepáticos.
\end{abstract}

Palavras-chaves: treino físico, desnutrição, stress oxidativo, ratos, aumento de peso, ingestão alimentar.

ABSTRACT

The aim of the present work was to study the effect of physical exercise on oxidative stress of undernourished rats. Thirty-two female Fischer rats were equally divided into Sedentary Control (SC), Trained Control (TC), Sedentary Undernourished (SU), and Trained Undernourished (TU) groups. The training protocol consisted of swimming continuously for thirty minutes per day five days a week for eight weeks. The TU group showed greater weight gain and final weight compared to the SU one. The values of total sulfhydryl and superoxide dismutase showed no increase of stress because of the training, in the same way that liver damage was not evident. The SC and SU animals showed higher serum glucose values than the TC and TU animals, respectively. However, the oral glucose tolerance test confirmed the significant increase only for the SC compared to the TC group. We conclude that the physical training increased weight gain and final weight in malnourished animals without increasing oxidative stress in serum nor modifying the food intake or causing liver damage.

Keywords: physical training, malnutrition, oxidative stress, rats, weight gain, food intake.

Artigo recebido a 01.11.2013; Aceite a 28.10.2014

${ }^{1}$ NUPEB - Núcleo de Pesquisas em Ciências Biológicas da Universidade Federal de Ouro Preto - UFOP Ouro Preto, $M G$, Brasil;

${ }^{2}$ CEDUFOP - Centro Desportivo da Universidade Federal de Ouro Preto - UFOP - Ouro Preto, MG, Brasil;

${ }^{3}$ Faculdade Estácio de Sá em Belo Horizonte - Belo Horizonte, MG, Brasil; Centro Universitário Metodista Izabela Hendrix - Belo Horizonte, MG, Brasil; Faculdade Santa Rita de Conselheiro Lafaiete - Conselheiro Lafaiete, $M G$, Brasil;

${ }^{4}$ UFJF - Universidade Federal Federal de Juiz de Fora campus de Governador Valadares - Governador Valadares, $M G$, Brasil;

${ }^{5}$ DECBI - Departamento de Ciências Biológicas da Universidade Federal de Ouro Preto - UFOP - Ouro Preto, $M G$, Brasil;

${ }^{6}$ DEALI - Departamento de Alimentos da Universidade Federal de Ouro Preto - UFOP - Ouro Preto, MG, Brasil;

* Autor correspondente: Centro Desportivo da Universidade Federal de Ouro Preto, Rua Dois, 110, Campus Universitário - Ginásio de Esportes, CEP: 35400-000, Ouro Preto - MG - Brasil.

E-mail: emerson@cedufop.ufop.br 


\section{INTRODUÇÃO}

Estudar a desnutrição precoce é importante, pois os seus efeitos podem ser irreversíveis, como demonstrado em animais (Winick \& Noble, 1966). Entretanto, existem evidências de que o treino físico é benéfico para animais desnutridos, pois acarreta modificações na composição corporal, diminuindo a percentagem de gordura da carcaça desses animais, com consequente aumento da massa magra (Crews, Fuge, Oscai, Holloszy, \& Shank, 1969).

Oldfors e Sourander (1985) demonstraram que o músculo-esquelético se adapta à desnutrição e que essa adaptação pode ser alterada pela modificação das demandas impostas ao músculo, como acontece no exercício.

O comportamento da glicemia frente ao efeito do treino físico apresenta controvérsia, pois há relatos de ausência de diferença (Luciano, 1991), aumento nas concentrações (Gobatto, 1993) e ainda uma alternância de aumentos e diminuições ao longo da experiência (Curi, Hell, \& Timo-Iaria, 1990). Como o metabolismo da glicose, assim como o das proteínas, também pode ser afetado pela desnutrição, e o fígado é o órgão central nesse processo - além de também sofrer com a desnutrição -, optouse por estudar esses metabolitos em conjunto, como marcadores da função hepática.

Somani, Frank e Rybak (1995) mostraram que tanto o exercício agudo como o exercício crónico são capazes de elevar os níveis de superóxido dismutase (SOD) em ratos. Em humanos, o exercício aeróbico resultou em aumento na atividade da SOD e na atividade da glutationa peroxidase (GPx) (Miyazaki et al., 2001). No entanto, a atividade da SOD, assim como a concentração de sulfidrilas totais no sangue de animais desnutridos treinados, ainda não foram estudadas.

O modelo animal de exercício permite a consolidação de importantes teorias para a prática de treino desportivo (Chimin, Araújo, Manchado-Gobatto, \& Gobatto, 2009), e avanços no entendimento dos efeitos do exercício que vão desde modificações morfológicas (Coura, Pacheco, Simões, Moraes, \& Campbell,
2012) até à resposta imunológica (Rocha, Nascimento, Rocha, Kashiwabara, \& Pinto, 2012).

Dentre os protocolos experimentais, tem sido dado um destaque especial ao exercício de natação (Chiyoda et al., 2009; Coura et al., 2012).

Portanto, foram objetivos deste trabalho estudar o efeito do treino físico da natação sobre marcadores séricos de stress oxidativo, da função hepática, do metabolismo da glicose, além de parâmetros bioquímicos e nutricionais de ratas desnutridas. Também foi objetivo caracterizar um modelo de desnutrição.

\section{MÉTODO}

Trata-se de um estudo do tipo experimental quantitativo.

\section{Amostra e grupos experimentais}

O projeto foi aprovado pelo Comité de Ética em Pesquisa da Universidade Federal de Ouro Preto, ofício CEP no 036/2008. Foram utilizadas inicialmente quarenta ratas Fischer distribuídas em dois grupos desde o nascimento até ao desmame (vinte e oito dias de vida) da seguinte forma: a) Grupo Controlo: dezasseis ratas que receberam dieta controlo - AIN-93M (Reeves, Nielsen, \& Fahey, 1993); b) Grupo Desnutrido: dezasseis ratas que receberam dieta hipoproteica (AIN-93M, modificado o teor de caseína para 6\%).

Após o desmame, os animais foram subdivididos em quatro grupos experimentais: a) Controlo Sedentário (CS): oito ratas alimentadas com dieta controlo, sem treino físico; b) Controlo Treinado (CT): oito ratas alimentadas com dieta controlo que realizaram treino físico; c) Desnutrido Sedentário (DS): oito ratas alimentadas com dieta hipoproteica, sem treino físico; e d) Desnutrido Treinado (DT): oito ratas alimentados com dieta hipoproteica que realizaram treino físico.

\section{Dietas e condições experimentais}

A dieta controlo - AIN-93M (Reeves et al., 1993) - tinha a seguinte composição em gramas para cada $1000 \mathrm{~g}$ de dieta: amido de milho 
$=715.5$ g; caseína $=147.0$ g; sacarose $=100$ g; óleo $=40.0 \mathrm{~g}$; fibra $=50.0 \mathrm{~g}$; mistura de minerais $=35.0 \mathrm{~g}$; mistura de vitaminas $=$ $10.0 \mathrm{~g}$; Colina $=2.5 \mathrm{~g}$.

A dieta hipoproteica apresentava as seguintes modificações em relação à dieta controlo (composição para cada $1000 \mathrm{~g}$ de dieta): amido de milho $=802.5 \mathrm{~g}$; caseína $=60.0 \mathrm{~g}$.

As misturas de vitaminas e de minerais foram manipuladas no próprio laboratório. As dietas foram igualmente preparadas e armazenadas sob refrigeração $\left(-4^{\circ} \mathrm{C}\right)$ até ao momento do uso. Os animais receberam água filtrada e o seu tipo de dieta ad libitum e foram mantidos em gaiolas individuais em ambiente com ciclos de claro/escuro de doze horas e temperatura de $25 \pm 1{ }^{\circ} \mathrm{C}$.

\section{Treino físico}

Os animais treinados foram adaptados ao meio líquido (água a $31 \pm 1{ }^{\circ} \mathrm{C}$ ) (Chimin et al., 2009; Chiyoda et al., 2009) da seguinte forma: no primeiro e no segundo dia, trinta minutos em piscina com água rasa; no terceiro e quarto dia, duas séries de quinze minutos com cinco minutos de intervalo em piscina com água a 50 $\mathrm{cm}$ de profundidade; e no quinto dia nadaram trinta minutos contínuos, mantendo a mesma profundidade do dia anterior. Da segunda à nona semana, os animais treinados repetiram a sessão do quinto dia de adaptação, cinco dias por semana. Os animais sedentários foram submetidos ao contacto com a água durante trinta minutos em piscina com água rasa, durante todo a experiência, para passarem pelo mesmo stress do manuseio diário.

\section{Teste Oral de Tolerância à Glicose (TOTG)}

O teste oral de tolerância à glicose foi realizado na última semana de experiência, 72 horas antes do sacrifício. Os animais permaneceram em jejum por 12 horas e foram recolhidas amostras de sangue da veia caudal antes (tempo 0) e após 30, 60 e 120 minutos da administração, por gavagem de uma solução de glicose (concentração final de $2 \mathrm{~g}$ de glicose por quilograma de peso corporal) (Moura et al., 2012).
Os níveis de glicose foram determinados através do glicosímetro digital (Accu-Check Active; Roche Diagnosis, Basel, Switzerland). Após a recolha dos dados, foi calculada a área total sob a curva para cada animal, aplicando a regra trapezoidal de forma automatizada através do software Prism ${ }^{\circledR}$ da GraphPad (versão 4.03 para Windows, GraphPad Software, San Diego, Califórnia, USA, www.graphpad.com). Os valores da área total sob a curva para cada animal foram agrupados e as comparações foram feitas conforme os restantes parâmetros.

\section{Eutanásia e recolha de material biológico}

Os animais foram pesados, anestesiados com isoflurano, e a eutanásia aconteceu por ensanguinação após um jejum de oito horas. Cada gaiola foi cuidadosamente inspecionada. $\mathrm{O}$ alimento e as bandejas colocadas sob as gaiolas para recolher as fezes foram retirados para garantir que o animal não tivesse acesso sequer às próprias fezes durante o período de jejum, evitando assim a coprofagia.

O sangue foi recolhido por secção do plexo braquial e posteriormente centrifugado a $10000 \mathrm{rpm}$ (rotações por minuto) durante quinze minutos para obtenção do soro e plasma, que foram guardados sob refrigeração (- 4 ${ }^{\circ} \mathrm{C}$ ). Todas as dosagens no soro ou plasma foram realizadas até quatro dias após a eutanásia.

\section{Dosagens bioquímicas}

As dosagens foram realizadas de acordo com as orientações do fabricante dos kits (Labtest Diagnóstica). Foram feitas dosagens das concentrações séricas de albumina, proteínas totais e glicose. Também foram determinadas as atividades da aspartato aminotransferase (AST) e da alanina aminotransferase (ALT). Para leitura das amostras foram utilizados espectrofotómetros Femto 600 S, 600 PLUS e $700 \mathrm{~S}$.

Os grupos sulfidrilas totais foram determinados através do reagente de Ellman (DNTB), conforme a metodologia proposta por Sedlak e Lindsay (1968). Os grupos sulfidrilas totais 
reagem com DNTB, formando um composto colorido que absorve luz a $412 \mathrm{~nm}$.

A determinação da Superóxido Dismutase no soro foi realizada através do kit Fluka número 19160 (USA), que utiliza um sistema de geração de aniões superóxido, xantina e xantina oxidase, avaliando a capacidade de a solução teste, sob condições padrões, inibir a reação do anião superóxido com o WST (2- (4 iodofenil) -3- (4-nitrofenil) -2H -5- tetrazolio). Esta reação, quando ocorrida, forma um composto denominado formazan que absorve luz a 450 $\mathrm{nm}$.

\section{Tratamento estatístico}

Os dados foram analisados quanto à normalidade, utilizando-se o teste de normalidade de D'Agostino e Pearson (omnibus K2 test). Depois de verificada a normalidade, os dados foram comparados pelo Teste $t$ não pareado, adotando $\mathrm{p}<0.05$ para aceitar as diferenças significativas. As análises estatísticas foram feitas utilizando-se o software Prism ${ }^{\circledR}$ da GraphPad (versão 4.03 para Windows, GraphPad Software, San Diego, Califórnia,
USA, www.graphpad.com). O tamanho do efeito (TE) foi calculado pelo $d$ de Cohen, através da fórmula: (Média 1 - Média 2) / Desvio Padrão do grupo controlo. Adotou-se a seguinte classificação para o TE: $<0.20=$ pequeno; $>0.50=$ moderado; $>0.80=$ elevado (Cohen, 1988).

\section{RESULTADOS}

O peso inicial apresentado na Tabela 1 precedeu o treino físico, portanto, não era esperado, e não foram observadas diferenças significativas entre os grupos por efeito do treino. Também não houve diferença para os níveis séricos de albumina, proteínas totais, superóxido dismutase (SOD) e sulfidrilas totais gerada pelo treino físico em nenhum dos dois estados nutricionais (Tabela 1). O modelo de desnutrição foi caracterizado por apresentar valores inferiores ao grupo controlo para quase todos os parâmetros representados na Tabela 1. O único parâmetro para o qual não houve diferença significativa foi sulfidrilas totais (Tabela 1).

Tabela 1.

Valores de Peso Inicial (PI), Albumina (Alb), Proteínas Totais (PT), Superóxido dismutase (SOD) e Sulfidrilas Totais (ST).

\begin{tabular}{c|ccccc}
\hline Grupos & PI (gramas) & Alb $(\mu \mathrm{mol} / \mathrm{L})$ & PT $(\mathrm{g} / \mathrm{L})$ & SOD $(\%)$ & ST $(\mu \mathrm{mol} / \mathrm{L})$ \\
\hline CS & $58.63 \pm 8.96^{*}$ & $495.30 \pm 45.81^{*}$ & $66.30 \pm 8.49^{*}$ & $75.02 \pm 4.99^{*}$ & $336.30 \pm 34.75$ \\
\hline CT & $58.44 \pm 8.62$ & $495.10 \pm 51.18$ & $69.06 \pm 10.42$ & $64.88 \pm 16.71$ & $310.70 \pm 30.81$ \\
\hline \multirow{2}{*}{ Teste $t$ - A } & $(\mathrm{p}=0.9668$, & $(\mathrm{p}=0.9948$, & $(\mathrm{p}=0.5706$, & $(\mathrm{p}=0.1224$, & $(\mathrm{p}=0.1413$, \\
& $d=0.00)$ & $d=0.00)$ & $d=0.33)$ & $d=0.94)$ & $d=0.81)$ \\
\hline DS & $22.00 \pm 3.27$ & $358.20 \pm 20.39$ & $59.17 \pm 3.11$ & $65.27 \pm 9.60$ & $307.80 \pm 24.26$ \\
\hline DT & $21.20 \pm 2.88$ & $356.50 \pm 18.04$ & $58.04 \pm 4.39$ & $65.42 \pm 11.13$ & $287.60 \pm 17.31$ \\
\hline \multirow{2}{*}{ Teste $t$ - B } & $(\mathrm{p}=0.4843$, & $(\mathrm{p}=0.8660$, & $(\mathrm{p}=0.5613$, & $(\mathrm{p}=0.9779$, & $(\mathrm{p}=0.0761$, \\
& $d=0.39)$ & $d=0.10)$ & $d=0.28)$ & $d=0.00)$ & $d=0.96)$ \\
\hline
\end{tabular}

Nota: O treino não gerou diferenças para os parâmetros apresentados nesta tabela. Valores estatísticos de cada teste $t$ para cada parâmetro indicado conforme comparações: CS (Controlo Sedentário) vs. CT (Controlo Treinado) (teste $t$ - A); DS (Desnutrido Sedentário) vs. DT (Desnutrido Treinado) (teste $t$ - B). ${ }^{*}$ Na caracterização do modelo, ou seja, na comparação CS vs. DS, teste $t$, o grupo DS apresentaram valores mais baixos nos parâmetros: Peso Inicial $(\mathrm{p}<0.0001, d=6.88)$; Albumina ( $\mathrm{p}<0.0001, d=3.93)$; Proteínas Totais $(\mathrm{p}=0.0428, d=1.15)$; Superóxido dismutase $(\mathrm{p}=0.0233, d=1.43)$. Para sulfidrilas totais não houve diferenças $(\mathrm{p}=0.0775, d=0.98)$. Valores representados em média \pm desvio padrão. $d=$ tamanho do efeito.

Os animais CT apresentaram maior ingestão alimentar do que os animais CS, ao passo que os animais DS e DT não apresentaram diferenças significativas (Figura 1). Na caracte- rização do modelo de desnutrição, os animais DS apresentaram valores inferiores de ingestão alimentar (Figura 1). 

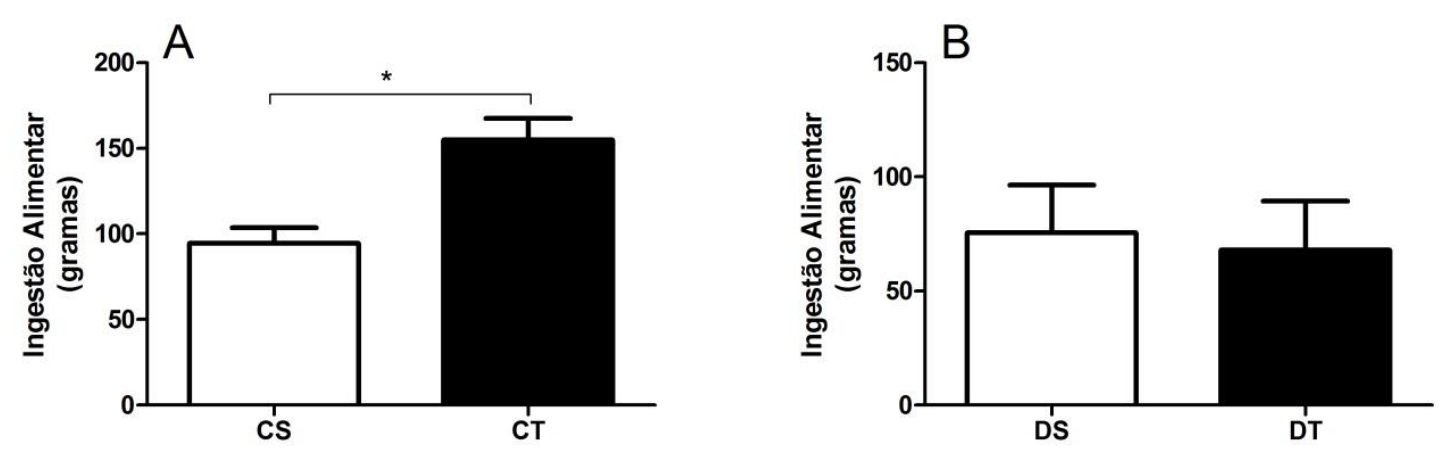

Figura 1. Ingestão alimentar de ratas CS (Controlo Sedentário) vs. CT (Controlo Treinado) (A); DS (Desnutrido Sedentário) vs. DT (Desnutrido Treinado) (B). Os animais CT apresentaram valores superiores aos dos animais CS $\left({ }^{*} \mathrm{p}<0.0001, d=5.65\right)(\mathrm{A})$, teste $t$. Não houve diferença significativa para teste $t$ entre os Desnutridos ( $\mathrm{p}=0.4903, d=0.38$ ) (B). Na caracterização do modelo de desnutrição, ou seja, na comparação CS vs. DS, teste $t$, o grupo DS apresentou valores inferiores $(C S=94.44 \pm 9.20$ vs. DS $=74.48 \pm 21.00 ; \mathrm{p}=$ $0.0347, d=1.17$ ). Valores representados em média \pm desvio padrão. $d=$ tamanho do efeito.
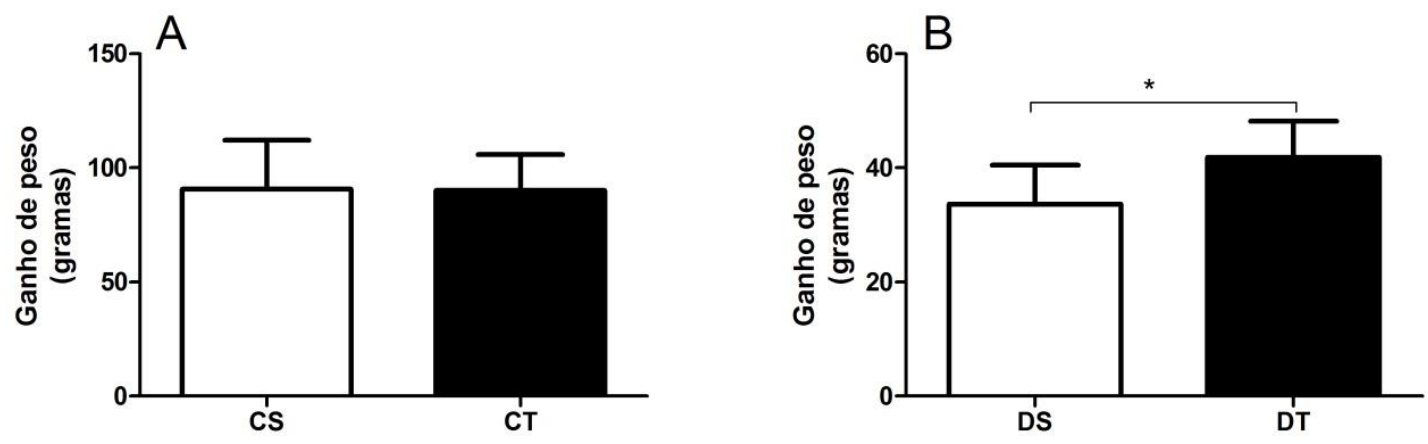

Figura 2. Ganho de peso de ratas CS (Controlo Sedentário) vs. CT (Controlo Treinado) (A); DS (Desnutrido Sedentário) vs. DT (Desnutrido Treinado) (B). Não houve diferença significativa para o teste $t$ entre Controlos ( $\mathrm{p}=0.9657, d=0.00)(\mathrm{A})$. Os animais DT apresentaram valores superiores aos dos DS $\left({ }^{*} \mathrm{p}=\right.$ $0.0088, d=1.33)(B)$, teste $t$. Na caracterização do modelo de desnutrição, ou seja, na comparação CS vs. DS, teste $t$, o grupo DS apresentou valores inferiores (CS $=90.64 \pm 21.44$ vs. DS $=33.67 \pm 6.78 ; \mathrm{p}<0.0001, d$ $=4.09)$. Valores representados em média \pm desvio padrão. $d=$ tamanho do efeito.
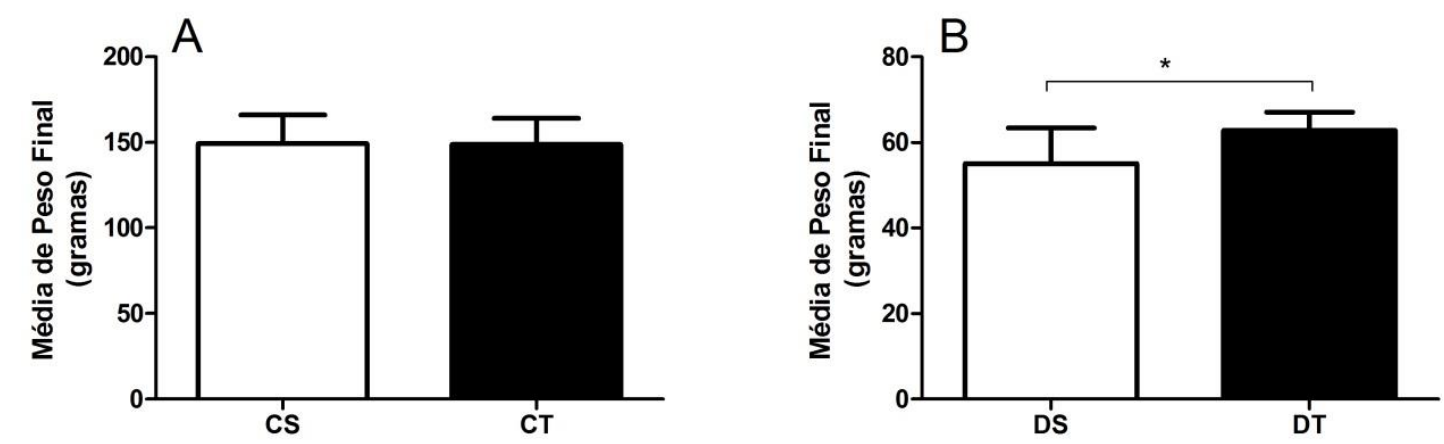

Figura 3. Peso final de ratas CS (Controlo Sedentário) vs. CT (Controlo Treinado) (A); DS (Desnutrido Sedentário) vs. DT (Desnutrido Treinado) (B). Não houve diferença significativa para o teste $t$ entre Contro$\operatorname{los}(\mathrm{p}=0.9423, d=0.06)(\mathrm{A})$. Os animais DT apresentaram valores superiores aos dos DS $\left({ }^{*} \mathrm{p}=0.0164, d=\right.$ 1.07) (B), teste $t$. Na caracterização do modelo de desnutrição, ou seja, na comparação CS vs. DS, teste $t$, o grupo DS apresentou valores mais baixos $(\mathrm{CS}=149.30 \pm 16.68$ vs. DS $=55.08 \pm 8.38$; $\mathrm{p}<0.0001, d=$ 7.98). Valores representados em média \pm desvio padrão. $d=$ tamanho do efeito. 
Os animais DT apresentaram maior aumento de peso e maior peso final do que os animais DS, enquanto os CS e CT não apresentaram diferenças significativas para o aumento de peso e peso final (Figuras 2 e 3 respetivamen-

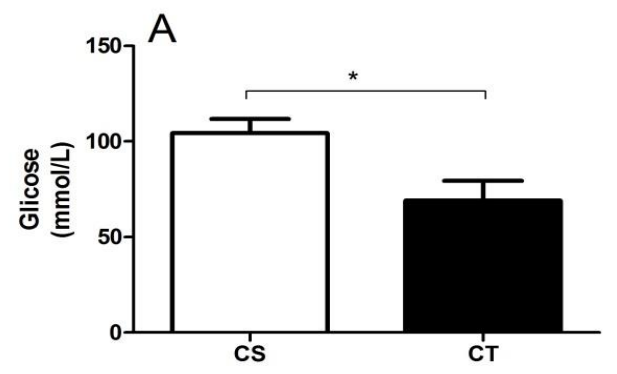

te). Na caracterização do modelo de desnutrição, os animais DS apresentaram valores mais baixos para aumento de peso, assim como para peso final (Figuras 2 e 3 respetivamente).

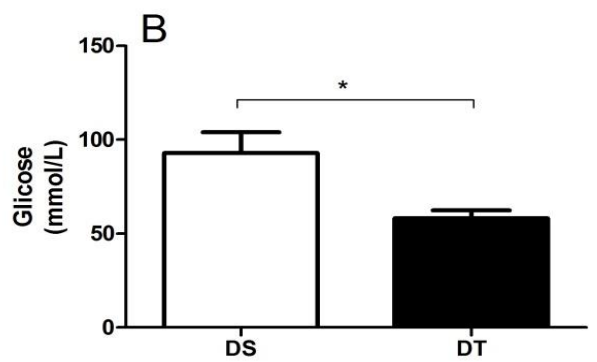

Figura 4. Valores séricos de glicose de ratas CS (Controlo Sedentário) vs. CT (Controlo Treinado) (A); DS (Desnutrido Sedentário) vs. DT (Desnutrido Treinado) (B). Os animais do grupo CS apresentaram valores superiores aos dos animais CT $\left({ }^{*} \mathrm{p}<0.0001, d=4.05\right)(\mathrm{A})$, teste $t$. Os animais do grupo DS apresentaram valores superiores aos dos animais DT $\left({ }^{*} \mathrm{p}<0.0001, d=4.10\right)(\mathrm{B})$, teste $t$. Na caracterização do modelo de desnutrição, ou seja, na comparação CS vs. DS, teste $t$, o grupo DS apresentou valores menores (CS $=104.40$ \pm 7.37 vs. $\mathrm{DS}=92.88 \pm 11.22 ; \mathrm{p}=0.0295, d=1.30$ ). Valores representados em média \pm desvio padrão. $d$ $=$ tamanho do efeito.
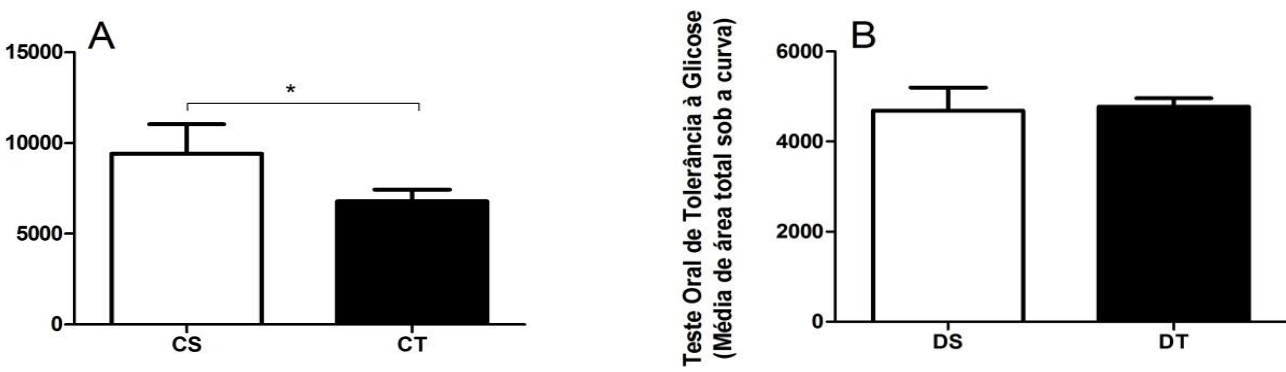

Figura 5. Teste oral de tolerância à glicose de ratas CS (Controlo Sedentário) vs. CT (Controlo Treinado) (A); DS (Desnutrido Sedentário) vs. DT (Desnutrido Treinado) (B). Os animais do grupo CS apresentaram valores superiores aos dos animais $\mathrm{CT}\left({ }^{*} \mathrm{p}=0.0042, d=2.12\right)(\mathrm{A})$, teste $t$. Não houve diferença significativa para o teste $t$ entre Desnutridos ( $\mathrm{p}=0.7080, d=0.22$ ) (B). Na caracterização do modelo de desnutrição, ou seja, na comparação CS vs. DS, teste $t$, o grupo DS apresentou valores mais baixos (CS $=9409 \pm 1621$ vs. DS $=4689 \pm 511.9 ; \mathrm{p}<0.0001, d=3.92)$. Valores representados em média \pm desvio padrão. $d=$ tamanho do efeito.

Os valores de glicemia sérica foram maiores nos animais CS comparados com CT e nos DS comparados com os DT (Figura 4). Já o teste oral de tolerância à glicose confirmou o aumento significativo apenas para os animais CS em relação aos CT, sendo, portanto, DS igual a DT (Figura 5). Em relação ao modelo de desnutrição, os animais DS apresentaram valores mais baixos para glicemia sérica, assim como para o teste oral de tolerância à glicose (Figuras 4 e 5 respetivamente).
A atividade de ALT foi maior nos animais sedentários em comparação aos treinados nos dois estados nutricionais (Figura 6). Enquanto a atividade de AST foi maior apenas nos animais CS em comparação aos CT (Figura 7). Na caracterização do modelo de desnutrição, os animais DS apresentaram valores de ALT mais elevados, assim como de AST (Figuras 6 e 7 respetivamente). 

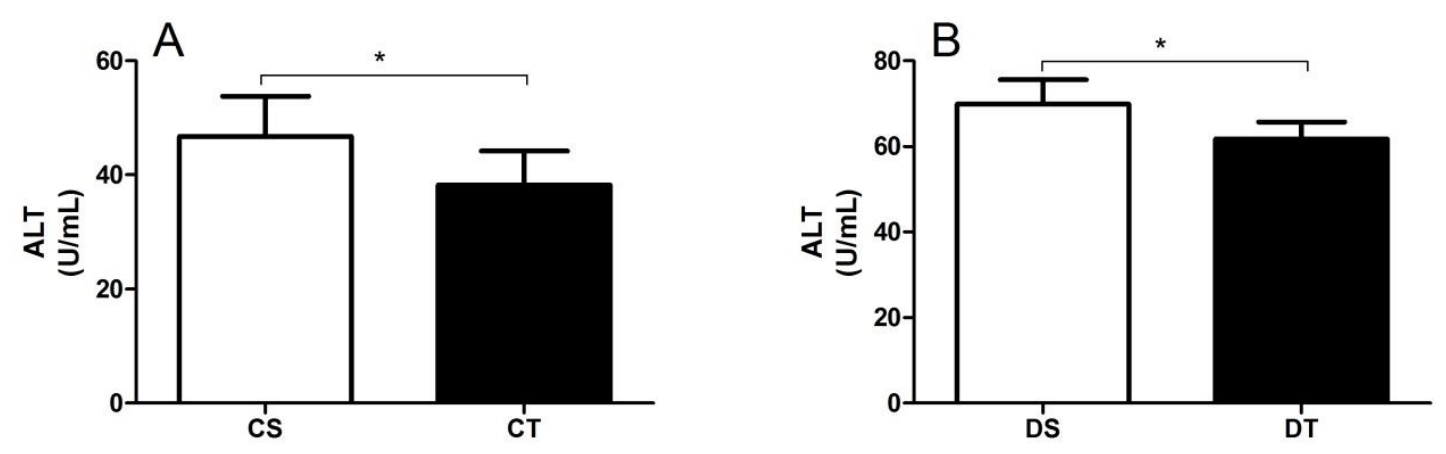

Figura 6. Atividade sérica de ALT (alanina aminotransferase) de ratas CS (Controlo Sedentário) vs. CT (Controlo Treinado) (A); DS (Desnutrido Sedentário) vs. DT (Desnutrido Treinado) (B). Os animais do grupo CS apresentaram valores superiores aos dos animais CT $\left({ }^{*} \mathrm{p}=0.0210, d=1.31\right)(\mathrm{A})$, teste $t$. Os animais do grupo DS apresentaram valores superiores aos dos animais DT ( $\left.{ }^{*} \mathrm{p}=0.0053, d=0.90\right)(\mathrm{B})$, teste $t$. Na caracterização do modelo de desnutrição, ou seja, na comparação CS vs. DS, teste $t$, o grupo DS apresentou valores mais altos $(\mathrm{CS}=46.75 \pm 7.05$ vs. $\mathrm{DS}=69.86 \pm 5.77 ; \mathrm{p}<0.0001, d=3.37)$. Valores representados em média \pm desvio padrão. $d=$ tamanho do efeito.
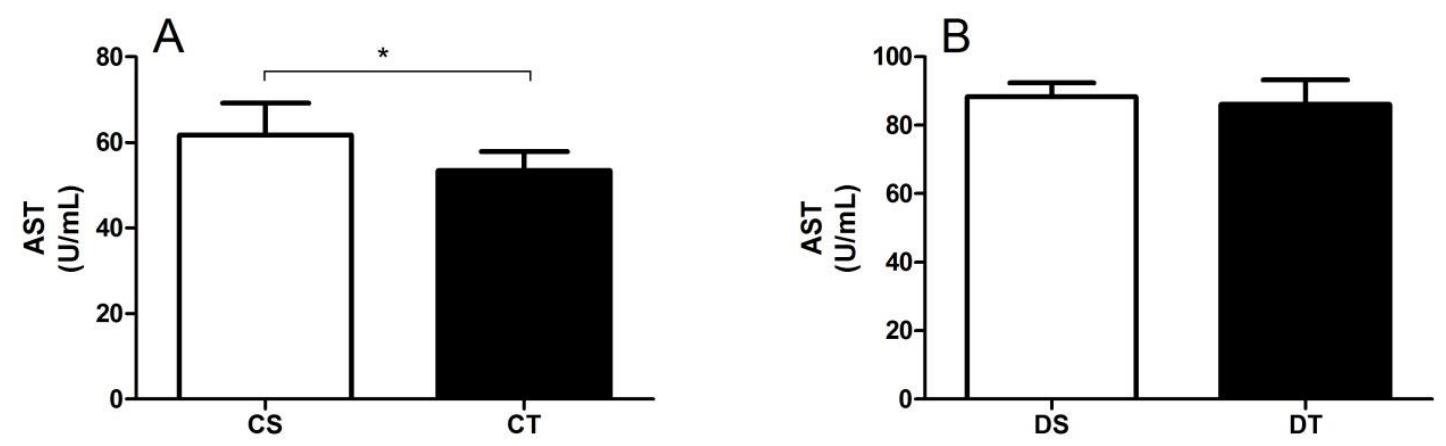

Figura 7. Atividade sérica de AST (aspartato aminotransferase) de ratas CS (Controlo Sedentário) vs. CT (Controlo Treinado) (A); DS (Desnutrido Sedentário) vs. DT (Desnutrido Treinado) (B). Os animais do grupo CS apresentaram valores superiores aos dos animais CT $\left({ }^{*} \mathrm{p}=0.0163, d=1.40\right)(\mathrm{A})$, teste $t$. Não houve diferença significativa para o teste $t$ entre Desnutridos $(\mathrm{p}=0.4764, d=0.35)$. Na caracterização do modelo de desnutrição, ou seja, na comparação CS vs. DS, teste $t$, o grupo DS apresentou valores mais elevados (CS = $61.75 \pm 7.40$ vs. $\mathrm{DS}=88.25 \pm 4.13 ; \mathrm{p}<0.0001, d=4.73)$. Valores representados em média \pm desvio padrão. $d=$ tamanho do efeito.

\section{DISCUSSÃO}

No final da experiência, os animais DT apresentaram maior aumento de peso e maior peso final em comparação com os DS, mas não apresentaram diferenças relativamente à ingestão alimentar. Esses dados justificariam a investigação do mecanismo pelo qual o protocolo de treino aeróbico agiria, contribuindo para o aumento de peso e de peso final dos animais desnutridos; e somam-se à discussão iniciada por Oldfors e Sourander (1985) de que o músculo-esquelético se adapta ao estado nutricio- nal e de que essa adaptação pode ser alterada pela modificação das demandas impostas ao músculo, como acontece no exercício. Na experiência de Oldfors e Sourander (1985) foram utilizadas dietas contendo $14 \%$ de proteína para animais controlo, dietas com $1.5 \%$ de proteína para o grupo desnutrido; e um protocolo de corrida em esteira rolante mais intenso e com uma maior duração (12 semanas) do que o da presente experiência. Os autores relataram ainda que animais desnutridos sedentários sofreram mais atrofia muscular do que 
animais exercitados e que o treino impediu a perda de mitocôndrias de animais desnutridos exercitados. Também existem relatos da ausência de diferença para o crescimento corporal de ratos DT comparados com ratos DS. Porém, com a ocorrência de modificações na composição corporal, verificou-se a diminuição da percentagem de gordura da carcaça de animais desnutridos com consequente aumento da massa magra (Crews et al., 1969).

Os animais CT apresentaram o aumento esperado em relação ao nível da ingestão alimentar, no entanto, para esses animais o protocolo de treino aparentemente não teve o volume e a intensidade necessários para gerar modificações no aumento de peso ou no peso final. Aumentar o volume ou a intensidade do treino para gerar adaptações nos animais CT poderia acarretar também uma maior mortalidade dos animais DT. Em função disso, optouse, nessa experiência, por manter um protocolo de treino factível por animais desnutridos provenientes da nossa colónia que receberam a mesma dieta. Porém, a introdução da dieta acontecia após o desmame concomitantemente com o início de um protocolo de treino idêntico ao aqui realizado (Oliveira, 2007).

Há relatos na literatura de que animais controlo exercitados não apresentaram diferenças para glicose sérica (Luciano, 1991), assim como existem trabalhos que mostram que o treino pode gerar o aumento desses níveis (Gobatto, 1993). Os resultados do presente estudo são opostos aos citados anteriormente, pois a glicose sérica dos grupos treinados nos dois estados nutricionais estudados foram inferiores aos valores apresentados pelos animais sedentários.

Curi, Hell, e Timo-Iaria (1990) realizaram um acompanhamento semanal da glicemia. Em quatro semanas foi observada uma alternância dos resultados: na primeira e última semana houve uma diminuição nos níveis de glicose sérica dos animais CT; verificou-se um aumento dos mesmos na terceira semana; e ausência de diferença na segunda semana. Todos esses dados indicam que a glicose sérica pode variar muito em função do tipo de treino, o que dificulta a formulação de uma explicação para tais modificações. No presente trabalho e nos trabalhos de Curi et al. (1990) e Luciano (1991), não foram utilizadas sobrecargas para aumentar a intensidade do exercício, ao passo que, no trabalho de Gobatto (1993), houve lugar a uma sobrecarga de $5 \%$ do peso corporal do animal.

$\mathrm{O}$ teste oral de tolerância à glicose confirmou uma diminuição significativa na área sob a curva para animais CT em relação aos CS. Tomados em conjunto com os dados de glicose sérica, esses dados indicam que o treino pode ter gerado, pelo menos para o grupo CT, um aumento na captação de glicose pelos tecidos, o que justificaria a sua diminuição na corrente sanguínea durante o teste oral de tolerância à glicose. Porém, não tivemos condições de testar essa hipótese. Gobatto (1997) não encontrou diminuição da glicose sérica como um efeito do treino, mas, no entanto, relatou um aumento significativo na captação de glicose pelo músculo sóleo isolado de animais treinados. Caso uma maior captação de glicose pelo músculo tenha acontecido para o grupo $\mathrm{CT}$ em função do treino na presente experiência, permaneceria obscura a maneira pela qual os animais DT apresentaram a sua glicose sérica diminuída e uma igualdade relativamente ao grupo DS quando foi testada a tolerância oral à glicose.

Koutedakis et al. (1993), comparando indivíduos treinados e não treinados, verificaram que o exercício aumenta de forma aguda a atividade de AST e da ALT, e que o nível de aptidão e a duração do exercício têm relação com as atividades dessas enzimas. Na presente experiência não se objetivou analisar os efeitos agudos do exercício sobre as atividades das duas enzimas, mas sim se o treino afetaria de forma crónica essas atividades. Portanto, a eutanásia aconteceu 72 horas após a última sessão de exercício. Os dados do presente estudo mostram que o treino não gerou nem potencializou uma disfunção hepática.

$\mathrm{O}$ oxigénio é essencial à vida. Contudo, durante a oxidação biológica, ele pode seguir vias 
alternativas que geram a produção de espécies reativas de oxigénio, danificando lipídos, proteínas e até mesmo o ADN celular. As células protegem-se contra os danos causados por essas espécies reativas através de enzimas de defesa como a superóxido-dismutase (SOD), catálase (CAT) e glutationa-peroxidase (GPx). A SOD converte o anião superóxido em peróxido de hidrogénio, o qual é neutralizado em água e oxigénio molecular pela atividade de outras enzimas antioxidantes, como a catálase e a glutationa-peroxidase.

O presente protocolo de exercício não modificou a atividade da SOD nem a concentração de sulfidrilas totais no soro dos animais. Somani et al. (1995) mostraram que tanto o exercício agudo como o exercício crónico são capazes de elevar os níveis de atividade da SOD nos glóbulos vermelhos isolados de ratos. Powers e Lennon (1999) explicam que, durante a fadiga, as defesas antioxidantes se tornam mais fracas, pelo que a melhoria da atividade de enzimas antioxidantes pode ajudar a suportar o exercício por mais tempo, atrasando a fadiga. Não encontrámos trabalhos que tenham medido os níveis de sulfidrilas totais no soro de animais submetidos a condições semelhantes às da presente experiência. Esses radicais também são utilizados como marcadores gerais de stress oxidativo no soro.

Em eritrócitos de humanos, o exercício aeróbico (diferentemente do anaeróbico) resultou em aumento da atividade da SOD e da atividade da GPx (Miyazaki et al., 2001), embora não tenha sido observada diferença para atividade da CAT. Além disso, a mudança de padrão de atividade em resposta ao exercício pode ser influenciada pelo grau de treino. Em atletas treinados, o exercício exaustivo foi capaz de aumentar a atividade da CAT e da GPx sem modificar a atividade da SOD de eritrócitos (Tauler, Gimeno, Aguiló, Guix, \& Pons, 1999).

Aumentos transitórios nas atividades de enzimas antioxidantes (CAT, SOD e GPx) podem ocorrem imediatamente (Terblanche, 1999) ou logo após o exercício (Leeuwen- burgh, Fiebig, Chandwaney, \& Ji, 1994). No entanto, o treino físico gera respostas adaptativas mais duradouras no tecido (Alessio, 1993).

No presente trabalho padronizou-se um protocolo de desnutrição que se iniciava no dia do nascimento dos filhotes, perdurando durante a lactação, com a duração de 28 dias. Para tal, foi utilizada uma dieta que continha $6 \%$ de caseína como fonte proteica. Assim, foi possível obter um grupo de animais DS com média de peso de 22 gramas, enquanto o grupo CS apresentava em média 58 gramas após o mesmo período. Depois da lactação, os animais permaneceram nove semanas com a mesma dieta, mas a metade dos animais desnutridos foi submetida ao treino físico, completando em torno de 91 dias de vida até à eutanásia.

O modelo foi caracterizado por apresentar os sinais clássicos de desnutrição, ou seja, diminuição de proteínas totais, de albuminas, da glicemia de jejum, do peso, da ingestão alimentar e do aumento de peso. Além disso, verificou-se um aumento da atividade de ALT e AST, indicadores de uma disfunção hepática. Acrescentamos o conhecimento sobre o comportamento da glicemia de animais desnutridos pelo presente protocolo face ao teste oral de tolerância à glicose, mostrando que a área sob a curva desses animais é duas vezes menor do que a área apresentada pelo grupo controlo. Interessantemente, o comportamento dos animais DT comparados ao dos DS face ao teste não foi semelhante ao apresentado por animais CT na comparação com os CS, gerando outra pergunta, a que é necessário responder, em relação ao metabolismo de glicose na desnutrição. Outra característica interessante do modelo foi a diminuição significativa apenas para a SOD no soro, sendo a concentração de sulfidrilas totais igual na comparação entre animais CS e DS.

Uma das limitações deste estudo está relacionada com o que o protocolo de exercício pode representar ao nível de exigência metabólica, considerando o volume e a intensidade do exercício aplicado no treino dos animais. Não foram realizados testes com essa finalidade. 
Um próximo passo pode ser determinar o que este protocolo representa para animais desnutridos, ou mesmo determinar a intensidade do exercício para a próxima experiência, utilizando o conceito de carga crítica, aplicando a metodologia utilizada por Chimin, Araujo, Manchado-Gobatto e Gobatto (2009); ou, alternativamente, determinar a intensidade do exercício baseado na capacidade aeróbica, conforme fizeram Coura, Pacheco, Simões, Moraes e Campbell (2012).

$\mathrm{O}$ volume de treino diário também pode ser modificado para 60 minutos, conforme foi feito nos trabalhos de Rocha, Nascimento, Rocha, Kashiwabara e Pinto (2012), com redução do número de semanas de treino de oito para seis. Ainda existe a opção de treinar por 60 minutos diários durante quatro semanas, adicionando $5 \%$ de sobrepeso ao animal (Chiyoda et al., 2009); ou 60 minutos diários com a manutenção das oito semanas de treino, estipulando uma sobrecarga correspondente a uma percentagem da transição metabólica, como fizeram Moura et al. (2012), modificando, assim, ao mesmo tempo, tanto o volume quando a intensidade do exercício.

\section{CONCLUSÕES}

Conclui-se que o treino físico influenciou o aumento de peso e do peso final dos animais desnutridos sem aumentar o stress oxidativo no soro, nem modificar a ingestão alimentar ou causar danos hepáticos. Também não causou prejuízo ao metabolismo da glicose mesmo em animais desnutridos. O modelo de desnutrição padronizado para esta experiência apresentou os sinais clássicos esperados.

\footnotetext{
Agradecimentos:

NUPEB - Núcleo de Pesquisa em Ciências Biológicas UFOP - Universidade Federal de Ouro Preto CEDUFOP - Centro Desportivo da Universidade Federal de Ouro Preto
}

Conflito de Interesses:

Nada a declarar.

\section{Financiamento:}

FAPEMIG via processo APQ-01353-11; CNPq via processo APQ-474227/2011-1; e CAPES via bolsa de estudos concedida a Emerson Cruz de Oliveira.

\section{REFERÊNCIAS}

Alessio, H. M. (1993). Exercise-induced oxidative stress. Medicine and Science in Sports and EXercise, 25(2), 218-224. http://doi.org/10.1249/00005768-19930200000010

Chimin, P., Araújo, G. G. de, Manchado-Gobatto, F. de B., \& Gobatto, C. A. (2009). Carga crítica durante treinamento contínuo e descontínuo na natação em ratos Wistar. Motricidade, 5(4), 45-58. http://doi.org/10.6063/motricidade.5(4).169

Chiyoda, A., Nakamura, P., Codogno, J., Junior, A. S., Leme, J. A., \& Luciano, E. (2009). Efeito da suplementação oral de arginina sobre a secreção de GH e metabolismo de lipídios em ratos Wistar treinados. Motricidade, 5(4), 1-11. http://doi.org/10.6063/motricidade.5(4).166

Cohen, J. (1988). Statistical Power Analysis for the behavioral sciences (2. ${ }^{\mathrm{a}}$ ed.). Hillsdale, $\mathrm{NJ}$ : Lawrence Erlbaum Associates.

Coura, M. A. de S., Pacheco, M. E., Simões, H. G., Moraes, J. F. V. N. de, \& Campbell, C. S. G. (2012). Estudo morfoquantitativo da parede da aorta de ratos wistar idosos treinados com exercício aeróbio. Motricidade, 8(4), 71-79. http://doi.org/10.6063/motricidade.8(4).1554

Crews, E. L., Fuge, K. W., Oscai, L. B., Holloszy, J. O., \& Shank, R. E. (1969). Weight, food intake, and body composition: effects of exercise and of protein deficiency. The American Journal of Physiology, 216(2), 359-363.

Curi, R., Hell, N. S., \& Timo-Iaria, C. (1990). Mealfeeding and physical effort. 1. Metabolic changes induced by exercise training. Physiology \& Behavior, 47(5), 869-873. http://doi.org/10.1016/0031-9384(90)90011$\mathrm{R}$

Gobatto, C. A. (1993). Alteraçôes metabólicas decorrentes do treinamento físico em ratos previamente desnutridos e recuperados (Dissertação de Mestrado em Biologia Funcional e Molecular). Universidade Estadual de Campinas, Campinas, SP. 
Gobatto, C. A. (1997). Metabolismo glicídico em músculo sóleo isolado de ratos desnutridos e recuperados: efeito dos ácidos graxos livres e do treinamento físico (Tese de Doutorado). Universidade Estadual de Campinas, Campinas, SP.

Koutedakis, Y., Raafat, A., Sharp, N. C., Rosmarin, M. N., Beard, M. J., \& Robbins, S. W. (1993). Serum enzyme activities in individuals with different levels of physical fitness. The Journal of Sports Medicine and Physical Fitness, 33(3), 252-257.

Leeuwenburgh, C., Fiebig, R., Chandwaney, R., \& Ji, L. L. (1994). Aging and exercise training in skeletal muscle: responses of glutathione and antioxidant enzyme systems. The American Journal of Physiology, 267(2 Pt 2), R439-445.

Luciano, E. (1991). Influências do Treinamento Físico sobre o Metabolismo de Carboidratos em Ratos Diabéticos Experimentais (Tese de Doutorado,). Universidade de São Paulo, São Paulo.

Miyazaki, H., Oh-ishi, S., Ookawara, T., Kizaki, T., Toshinai, K., Ha, S., ... Ohno, H. (2001). Strenuous endurance training in humans reduces oxidative stress following exhausting exercise. European Journal of Applied Physiology, 84(1-2), 1-6. http://doi.org/10.1007/s004210000342

Moura, L. P. de, Gomes, R. J., Leme, J. A., Voltarelli, F. A., Ribeiro, C., Moura, R. F. de, ... Mello, M. R. de. (2012). Insulina pancreática de ratos diabéticos tipo 1 submetidos a um protocolo de treinamento físico individualizado. Motricidade, $8(1), \quad 23-32$. http://doi.org/10.6063/motricidade.8(1).234

Oldfors, A., \& Sourander, P. (1985). Effects of training on skeletal muscle in protein-deprived rats. Journal of the Neurological Sciences, 69(1-2), $1-8$. $510 \times(85) 90002-4$ http://doi.org/10.1016/0022-

Oliveira, E. C. (2007). Avaliação bioquímica nutricional de animais treinados submetidos à desnutrição e recuperação nutricional (Dissertação de Mestrado em Ciências Biológicas). Universidade Federal de Ouro Preto, Ouro Preto.
Powers, S. K., \& Lennon, S. L. (1999). Analysis of cellular responses to free radicals: focus on exercise and skeletal muscle. Proceedings of the Nutrition Society, 58(04), 1025-1033. http://doi.org/10.1017/S0029665199001342

Reeves, P. G., Nielsen, F. H., \& Fahey, G. C. (1993). AIN-93 purified diets for laboratory rodents: final report of the American Institute of Nutrition ad hoc writing committee on the reformulation of the AIN-76A rodent diet. The Journal of Nutrition, 123(11), 1939-1951.

Rocha, L. L. V., Nascimento, R. D., Rocha, L. H. L., Kashiwabara, T. B., \& Pinto, M. V. M. (2012). Avaliação do benefício do exercício físico moderado na resposta imunológica de ratos submetidos ao estresse de contenção. Motricidade, 8(Supl. $\quad 2$ ), 1055-1064. http://doi.org/10.6063/motricidade.8(0).649

Sedlak, J., \& Lindsay, R. H. (1968). Estimation of total, protein-bound, and nonprotein sulfhydryl groups in tissue with Ellman's reagent. Analytical Biochemistry, 25(1), 192-205. http://doi.org/10.1016/0003-2697(68)900924

Somani, S. M., Frank, S., \& Rybak, L. P. (1995). Responses of antioxidant system to acute and trained exercise in rat heart subcellular fractions. Pharmacology, Biochemistry, and Behavior, 51(4), 627-634. http://doi.org/10.1016/0091-3057(94)00427$\mathrm{K}$

Tauler, P., Gimeno, I., Aguiló, A., Guix, M. P., \& Pons, A. (1999). Regulation of erythrocyte antioxidant enzyme activities in athletes during competition and short-term recovery. Pflügers Archiv: European Journal of Physiology, 438(6), 782-787.

Terblanche, S. E. (1999). The effects of exhaustive exercise on the activity levels of catalase in various tissues of male and female rats. Cell Biology International, 23(11), 749-753. http://doi.org/10.1006/cbir.1999.0442

Winick, M., \& Noble, A. (1966). Cellular response in rats during malnutrition at various ages. The Journal of Nutrition, 89(3), 300-306.

Todo o conteúdo da revista Motricidade está licenciado sob a Creative Commons, exceto quando especificado em contrário e nos conteúdos retirados de outras fontes bibliográficas. 